\title{
Scientific author names: errors, corrections, and identity profiles
}

\author{
Armen Yuri Gasparyan*1, Marlen Yessirkepov², Alexey N. Gerasimov³, Elena I. Kostyukova ${ }^{4}$, George D. Kitas ${ }^{1,5}$ \\ 'Departments of Rheumatology and Research and Development, Dudley Group NHS Foundation Trust, Russells Hall Hospital, Dudley, \\ West Midlands, UK \\ 2Department of Biochemistry, Biology and Microbiology, South Kazakhstan State Pharmaceutical Academy, Shymkent, Kazakhstan \\ ${ }^{3}$ Department of Statistics and Econometrics, Stavropol State Agrarian University, Stavropol, Russian Federation \\ ${ }^{4}$ Department of Accounting Management, Faculty of Accounting and Finance, Stavropol State Agrarian University, Stavropol, Russian \\ Federation \\ ${ }^{5}$ Arthritis Research UK Epidemiology Unit, University of Manchester, Manchester, UK
}

*Corresponding author: a.gasparyan@gmail.com

\begin{abstract}
Authorship problems are deep-rooted in the field of science communication. Some of these relate to lack of specific journal instructions. For decades, experts in journal editing and publishing have been exploring the authorship criteria and contributions deserving either co-authorship or acknowledgment. The issue of inconsistencies of listing and abbreviating author names has come to the fore lately. There are reports on the difficulties of figuring out Chinese surnames and given names of South Indians in scholarly articles. However, it seems that problems with correct listing and abbreviating author names are global. This article presents an example of swapping second (father's) name with surname in a 'predatory' journal, where numerous instances of incorrectly identifying and crediting authors passed unnoticed for the journal editors, and no correction has been published. Possible solutions are discussed in relation to identifying author profiles and adjusting editorial policies to the emerging problems. Correcting mistakes with author names post-publication and integrating with the Open Researcher and Contributor ID (ORCID) platform are among them.
\end{abstract}

Key words: authorship; author names; science communication; identity; editorial policies

\section{Scale of the problem with author names}

Authorship problems are not new to the publishing industry, and probably existed in the classical writings long before the launch of the first scholarly journal, the Philosophical Transactions of the Royal Society (1665). The notorious case of an English poet and playwright William Shakespeare with ambiguous authenticity of his portraits, spellings of surname, and writing styles, which were recorded in the annals of history, teaches us a lesson. The centuries-long uncertainties over his identity and debates over the authorship of his poems, claimed by some to be ghost-written by noble people with exquisite language close to the royal court, continue well into the $21^{\text {st }}$ century $(1,2)$. For centuries, identifying and crediting appropriate authors has been viewed as a daunting task for publishers and distributors of information. With the fast-growing number of periodicals and ever-increasing number of co-authors in the current scholarly articles, authorship problems are becoming more complex and not easily discernible (3).

The scale of the problem is reflected in the exponential increase of scholarly items tagged with the term "authorship" in PubMed with the first record appearing in 1895 and reaching a peak level of 372 articles in 2014 (as of March 20, 2016). Overall, there are 5899 tagged items in PubMed, including 1891 (32\%) on the authorship criteria and only 129 (2.2\%) on author names. 
In fact, authorship criteria and contributorship are still widely discussed and are predominant topics in the field. Recommendations are offered to all those engaged in science communication to raise awareness of what constitutes ethical authorship (4). Pointers on upgrading journal instructions have also been developed, though listing and abbreviating author names has been overlooked entirely (5).

Properly listing scientific authors in an article is the first step toward ethical and successful writing (6). Strict adherence to the journal authorship policy and format of author names make the initial impression on the reviewers, editors, and other readers of the article. Editors and publishers overlooking the accuracy of adhering to the authorship regulations expose their journals to misconduct and limit their chances of post-publication communication.

Authors of scholarly articles deserve to be properly identified with their real names and credited to continuously contribute to science communication (7). The issue of identification often arises when research fellows search for highly skilled international mentors for their under- and postgraduate studies and research. Journal editors also encounter the same issue when they process submissions and pick potential reviewers by evaluating the corresponding authors' profiles. They may also need photographs of the authors to credit and preserve profiles of the most influential scholars for the future (8). On the positive side, by recording authors' correct names and linking to their affiliations, editors simultaneously credit academic institutions and other organizations where scholars conduct research. On the negative side, tracking the most prolific authors' records and analysing their conflicting relationships with pharmaceutical companies enabled questioning the trustworthiness of some 'evidence-based' publications influencing diagnostic and curative standards (9). Here we are reminded of numerous practice guidelines where authors are "big" names with extensive relationships with pharmaceutical companies.

Funding agencies processing grant applications pay due attention to the names of the listed investigators and predict potential academic output by evaluating previous publications of prolific authors, and particularly principal investigators. Finally, authors' names and their profiles are carefully evaluated by editors, publishers, and representatives of related academic institutions when disputes arise over the authors' contributions and inappropriate authorship, which may eventually lead to retractions (10).

In the era of digitization, the availability of various platforms for archiving scholarly articles and building up individual profiles makes it easier to identify and evaluate academic records. Examples of such platforms are the Scopus Author Identifier (Elsevier), ResearcherID (Thomson Reuters), PubMed, Google Scholar Citations, ResearchGate, and Linkedln. Eminent scientists with life-long achievements may also have Wikipedia profiles. Authors who publish articles indexed by Scopus, Web of Science, PubMed, and visible in Google Scholar have their records, which are visible to the database users. The database indexers process author names in the first place and link to their articles. The authors who correctly spell and list their own names in the author by-lines from their very first publication contribute to the expedient recording of academic output and build-up of the individual platforms. The Scopus Author Identifier incorporates different name formats of the same author within a single digital identifier, which partly resolves the issue of author name disambiguation. In case of different, automatically created author profiles in Scopus, the scholars, representatives of their institutions, and other interested persons may request merges.

To correctly identify authors, indexers refer to the submissions from current and previous primary sources (journals), linked affiliations, and geographical locations, to name just a few identifying options. Affiliations and geographic origin may change throughout an academic career, which is why many other factors should be considered to maintain profile of an individual scientific author in a database.

For research purposes, and particularly for distinguishing the gender of the main contributors, the authors' scholarly profiles may be evaluated alongside their records on the institutional websites and 
social networking platforms to find photographs and biographical notes (11). However, even such a detailed processing of author records fails to identify gender in 3\% of cases, which points to the need for more advanced and complex author identifiers.

\section{Confusion with author names}

For decades, the issue of incorrectly abbreviated, misspelled, and misplaced first, middle (fathers') names, and surnames has affected scientific authors globally. Authors and editors alike are equally responsible for erroneous and inconsistent records, which inadvertently affect author profiles and citation rankings (12). Different national traditions of name attribution and placement in the author by-lines have resulted in the inconsistencies. In particular, concerns have been raised over the identity of Chinese authors with similarly abbreviated but different first names (13). Confusion with figuring out surnames of Chinese authors has led to erroneous records in the metadata of related scholarly articles and bibliographic lists (14). Likewise, the Greek custom of formal referral to scholars by placing surname first resulted in forename and surname swapping in scholarly articles (15). South Indian author names have been mistakenly recorded in their articles because of the traditional absence of their surnames and ambiguous abbreviation of their first and second names (16).

Technical editors of most Russian journals add to the complexity of the author names problem by deliberately translating author names from Russian to English and supplying global indexers with variable spellings of the same names (e.g., Esirkepov and Yessirkepov).

There are also ambiguities with Middle Eastern, and particularly Iranian names, which may be inconsistently linked to first and second names and references to geographical locations or birth places of the authors (Isfahani, Mashhadi, Tehrani), and mistakenly abbreviated (e.g., Ahmad-Reza may be spelled as Ahmadreza and abbreviated as A.-R. or A.). Besides, an Islamic title of respect, Seyed, is also variably recorded as first name or omitted (e.g., Seyed Hesameddin Abbasi, Seyed Abbasi, Hesameddin Abbasi).
There have been numerous instances of journal editors' unawareness of their international authors' traditions and carelessness of both editors and authors throughout the manuscript processing, proofreading and publishing that perpetuated errors with abbreviation and placement of names. One of the striking incidents of swapping surnames and middle (fathers') names took place in the 'predatory' journals. Predatory journals are known to predominantly publish articles of those who lack writing and publishing experience (17), which could be the main cause of erroneous recording of their names. One such example is the Biosciences, Biotechnology Research Asia, which is indexed by Scopus, Web of Science, and listed on Jeffrey Beall's blog (available at: https://scholarlyoa.com/individual-journals/). The journal editors' lack of awareness of the Russian, Slavic and Soviet custom of having patronymic placed in the middle between given name and surname wasted numerous Russian and other Eurasian authors' efforts and damaged their profiles of publication activity. In an article from the Biosciences, Biotechnology Research Asia, where Shibikeyeva (surname) Aigerim (given name) Meirambayevna (patronymic) is listed as a corresponding author, Meirambayevna is recorded as surname, and bibliographic databases subsequently listed her as Meirambayevna S.A. instead of Shibikeyeva A.M. (18). The same errors with swapping names have surfaced in numerous other articles from the same journal over the past few years without any post-publication corrections.

\section{Corrections and possible solutions}

Various errors with author names can be traced across published scholarly articles. Even high-impact journals are not immune to such errors. A recent analysis of the authorship policies of 600 journals with impact factors revealed that only $62.5 \%$ of the journals, and primarily those in the field of biomedical and social sciences, declared a policy aimed at providing guidance over the authorship criteria and related ethical norms (19). None of the sampled journals presented points on the standards of listing and abbreviating names. Statements on author names and points for non-Anglophone authors with author naming and listing traditions 
different from the Western standards are supposed to help avoid some of the related technical problems.

Reputable publishers have implemented a postpublication correction policy. In a landmark analysis of PubMed-indexed articles with Greek forenames and surnames swapped, 113 articles published between 1997 and 2008 in 101 journals from diverse biomedical subject categories were retrieved (15). There were 5 articles with errors in author names published in the same journal (International Urology and Nephrology). Author names were corrected in errata related to only 20 (17.7\%) articles after a median of 6.5 months. It appeared that time to name correction was shorter in journals with high impact factor. Such a trend is in agreement with a previous account on corrections and retractions appearing mostly in widely visible periodicals, which attract attention of the global scientific community (10).

Many publishers have now joined the CrossMark ${ }^{\circledR}$ global initiative, which allows correction of publishers' and authors' errors in errata and corrigenda, respectively, with amendments incorporated in the published online versions of the articles (http://www.crossref.org/crossmark/).

More importantly, the Open Researcher and Contributor ID (ORCID) initiative was launched in October 2012 to overcome author name ambiguities and link unique digital IDs with names in articles (20). As of March 22, 2016, there are 2,058,997 registered individuals with ORCID profiles. Setting such a unique digital profile allows an individual to show off his/her name and academic achievements to the scientific community. The ORCID IDs can be particularly useful for authors with common, inconsistently recorded names, and those with related national traditions (e.g. Chinese, Korean, Japanese, Iranian, Russian). The identification of authors, reviewers and editors by referring to their IDs is increasingly practised in scholarly journals. More than 100 publishers have already endorsed the ORCID initiative and more than 1000 journals have integrated their websites and editorial management systems with the registry (21). In a move to improve visibility of publications, the Korean Association of Medical Journal Editors with
TABLE 1. Options for identifying and comprehensively evaluating scientific authors

Accurately spelled / abbreviated first, middle name(s) and
surname
Linked affiliations
Postal and electronic mail contacts
Signature
Photographs in articles and on institutional and individual
platforms
Biographical notes on academic, institutional, and social
portals, including Wikipedia pages
Video abstracts of articles
Open Researcher and Contributor ID (ORCID)
Academic records on bibliographic databases/platforms
(PubMed, Scopus, Web of Science, Google Scholar)
Profile on scholarly networking sites (ResearchGate ${ }^{\oplus}$,
Linkedln $^{\oplus}$ )
Profile on social networking sites (Facebook ${ }^{\oplus}$, Twitter $^{\oplus}$ )
Academic writing style

255 member-journals set a good example by endorsing the ORCID initiative and listing the author IDs in the footnotes of each article (22).

There are now several options to properly identify scientific authors (Table 1). All these options may be employed to resolve the issue in complex scenarios. The journal editors' familiarity with all these options can be instrumental for incorporating related points in their instructions for authors, correctly identifying author names at the proof reading, and connecting published articles with author identifiers. The renewed and enforced instructions may potentially resolve the issue of author name ambiguities and avoid related errors. Technical editors are in the best position to ask the authors to correctly identify their first and last names and preferred abbreviations at the manuscript proof reading.

To a certain degree, editorial policies over the identification and correct author names will resolve problems with inappropriate authorship and provide the readers, indexers, and specialists in information and scientometrics with trustworthy scientific accounts.

\section{Potential conflict of interest}

None declared. 


\section{References}

1. Marsden J, Budden D, Craig H, Moscato P. Language individuation and marker words: Shakespeare and his Maxwell's demon. PLoS One 2013;8:e66813. http://dx.doi. org/10.1371/journal.pone.0066813.

2. Boyd RL, Pennebaker JW. Did Shakespeare write double falsehood? Identifying individuals by creating psychological signatures with text analysis. Psychol Sci 2015;26:570-82. http://dx.doi.org/10.1177/0956797614566658.

3. Vučković-Dekić L. Multiauthorship and false authorship: why worrying about this? Srp Arh Celok Lek 2014;142:63740. $h$ ttp://dx.doi.org/10.2298/SARH1410637V.

4. Gasparyan AY, Ayvazyan L, Kitas GD. Authorship problems in scholarly journals: considerations for authors, peer reviewers and editors. Rheumatol Int 2013;33:277-84. http:// dx.doi.org/10.1007/s00296-012-2582-2.

5. Gasparyan AY, Ayvazyan L, Gorin SV, Kitas GD. Upgrading instructions for authors of scholarly journals. Croat Med J 2014;55:271-80. http://dx.doi.org/10.3325/ cmj.2014.55.271.

6. Hong ST. Ten tips for authors of scientific articles. J Korean Med Sci 2014;29:1035-7. http://dx.doi.org/10.3346/ jkms.2014.29.8.1035.

7. Bohannon J. Scientific publishing. Fight over author pseudonyms could flare again. Science 2016;351:902. http:// dx.doi.org/10.1126/science.351.6276.902

8. Behrents RG. Author! Author! Am J Orthod Dentofacial Orthop 2015;148:1-3. http://dx.doi.org/10.1016/j.ajodo.2015.04.024.

9. Holleman F, Uijldert M, Donswijk LF, Gale EA. Productivity of authors in the field of diabetes: bibliographic analysis of trial publications. BMJ 2015;351:h2638. http://dx.doi. org/10.1136/bmj.h2638.

10. Gasparyan AY, Ayvazyan L, Akazhanov NA, Kitas GD. Selfcorrection in biomedical publications and the scientific impact. Croat Med J 2014;55:61-72. http://dx.doi.org/10.3325/ cmj.2014.55.61.

11. Filardo G, da Graca B, Sass DM, Pollock BD, Smith EB, Martinez MA. Trends and comparison of female first authorship in high impact medical journals: observational study (19942014). BMJ 2016;352:i847. http://dx.doi.org/10.1136/bmj. i847.
12. Kurien BT. Name variations can hit citation rankings. Nature 2008;453:450. http://dx.doi.org/10.1038/453450a.

13. Qiu J. Scientific publishing: identity crisis. Nature 2008;451:766-7. http://dx.doi.org/10.1038/451766a.

14. Cheng TO. The continuing confusion in figuring out the surname of a Chinese author: a proposed solution. Chin J Integr Med 2012;18:243-4. http://dx.doi.org/10.1007/s11655012-1061-7.

15. Trikalinos TA. Does it mean anything if your own name is wrong in your published paper? FASEB J 2009;23:2345-8. http://dx.doi.org/10.1096/fj.09-130922.

16. Puniamoorthy N, Jeevanandam J, Narayanan Kutty S. Give south Indian authors their true names. Nature 2008;452:530. http://dx.doi.org/10.1038/452530d.

17. Xia J, Harmon JL, Connolly KG, Donnelly RM, Anderson MR, Howard HA. Who publishes in "predatory" journals? J Assoc Inf Sci Technol 2015;66:1406-17. http://dx.doi.org/10.1002/ asi.23265.

18. Shibikeyeva AM, Yeleshev RY, Dzhumabekovna MA, Leonidovich, Sagynbay K. Yield formation and consumption of fertilizers by cabbage in long-term and systematic use of mineral fertilizers. Biosciences Biotechnology Research Asia 2014;11:1187-92. http://dx.doi.org/10.13005/bbra/1504.

19. Resnik DB, Tyler AM, Black JR, Kissling G. Authorship policies of scientific journals. J Med Ethics 2016;42:199-202. http:// dx.doi.org/10.1136/medethics-2015-103171.

20. Gasparyan AY, Akazhanov NA, Voronov AA, Kitas GD. Systematic and open identification of researchers and authors: focus on open researcher and contributor ID. J Korean Med Sci 2014;29:1453-6. http://dx.doi.org/10.3346/ jkms.2014.29.11.1453.

21. Anstey A. How can we be certain who authors really are? Why ORCID is important to the British Journal of Dermatology. Br J Dermatol 2014;171:679-80. http://dx.doi. org/10.1111/bjd.13381.

22. Gasparyan AY, Hong ST. Celebrating the achievements and fulfilling the mission of the Korean Association of Medical Journal Editors. J Korean Med Sci 2016;31:333-5. http:// dx.doi.org/10.3346/jkms.2016.31.3.333. 